\title{
KONTRIBUSI PENDAPATAN TENAGA KERJA WANITA PADA USAHA EMPING MELINJO TERHADAP PENDAPATAN KELUARGA DI DESA PLUMBON KECAMATAN LIMPUNG KABUPATEN BATANG
}

\author{
Miratus Saadah*, Sri Wahyuningsih, Shofia Nur Awami, Lutfi Aris Sasongko \\ Program Studi Agribisnis \\ Fakultas Pertanian Universitas Wahid Hasyim Semarang \\ Jl. Menoreh Tengah X No.22, Sampangan, Gajahmungkur, Semarang 50232 \\ *Corresponding author: miratuss $19 @$ gmail.com
}

\begin{abstract}
The purpose of this research is to find out 1)the reasons why women workers work in melinjo chips, 2)the average allocation of women's work hours in melinjo chips, 3)the contribution of women workers to melinjo chips businesses on family income and, 4)factors that influence women's income contribution to the melinjo chips business. Respondents were taken by purposive sampling with the number of respondents as many as 45 women workers in 3 business ventures in Plumbon Village, Limpung District, Batang Regency. The results showed that the reason of women work in the business seen from dominant economic factors to help husbands find additional household income. While social factors, namely to fill spare time. The average working hours of women workers in melinjo business is 8 hours/day. The contribution of women workers in the emping melinjo business to family income was 33,68 percent. $R^{2}$ value obtained using multiple linear regression models of 0.686 shows that the proportion of the influence of independent variables (women's income, husband's income and the number of family dependents) on the dependent variable in the form of women's income contribution to the melinjo chips business was $68.6 \%$ while the remaining $31.4 \%$ is influenced by other variables not found in the linear regression model in this study. The results of the F-test and t-test showed that the variance in women's income, husband's income and the number of family dependents had a significant effect on women's income contribution.
\end{abstract}

Keywords: contribution, chips, melinjo, women workers

\begin{abstract}
Abstrak: Tujuan penelitian ini adalah untuk mengetahui 1) alasan tenaga kerja wanita bekerja pada usaha emping melinjo 2) rata-rata alokasi jam kerja tenaga kerja wanita pada usaha emping melinjo, 3) besar kontribusi tenaga kerja wanita pada usaha emping melinjo terhadap pendapatan keluarga dan, 4) faktor yang mempengaruhi kontribusi pendapatan wanita pada usaha emping melinjo. Pengambilan responden dilakukan secara purposive sampling dengan jumlah responden sebanyak 45 orang tenaga kerja wanita pada 3 usaha dagang di Desa Plumbon Kecamatan Limpung Kabupaten Batang. Hasil penelitian menunjukkan bahwa alasan wanita bekerja pada usaha pembuatan emping melinjo dilihat dari faktor ekonomi dominan untuk membantu suami mencari tambahan penghasilan rumah tangga. Sedangkan faktor sosial, yaitu untuk mengisi waktu luang. Rata-rata jam kerja tenaga kerja wanita pada usaha emping melinjo adalah 5 jam/hari atau $20,8 \%$. Kontribusi tenaga kerja wanita pada usaha emping melinjo terhadap pendapatan keluarga adalah $33,68 \%$. Nilai $R^{2}$ yang diperoleh dengan menggunakan model regresi linier berganda sebesar 0,686 menunjukkan bahwa proporsi pengaruh variabel bebas (pendapatan wanita, pendapatan suami dan jumlah tanggungan keluarga) terhadap variabel terikat berupa kontribusi pendapatan wanita pada usaha emping melinjo sebesar $68,6 \%$ sedangkan sisanya $31,4 \%$ dipengaruhi oleh variabel lain yang tidak terdapat pada model regresi
\end{abstract}


linier dalam penelitian ini. Hasil uji $\mathrm{F}$ dan uji-t menunjukkan bahwa variabel pendapatan wanita, pendapatan suami dan jumlah tanggungan keluarga berpengaruh nyata terhadap kontribusi pendapatan wanita.

Kata Kunci: kontribusi, emping, melinjo, tenaga kerja wanita

\section{PENDAHULUAN}

Keterbatasan wanita dalam pendidikan dan umur menyebabkan wanita mau bekerja pada semua jenis pekerjaan dan umumnya bekerja di sektor informal. Meningkatnya peluang kerja bagi wanita di sektor industri dikarenakan oleh beberapa hal. Pertama, dalam memasuki usaha tersebut tidak menuntut jenjang pendidikan yang tinggi. Kedua, kondisi yang dituntut oleh tenaga kerja perempuan lebih ringan dari tenaga kerja laki-laki.

Aktivitas wanita untuk bekerja memperoleh penghasilan pada dasarnya dilakukan untuk membantu suami menstabilkan perekonomian dalam keluarga, tidak selesai sekolah, banyaknya anggota tanggungan dalam keluarga, ingin mengembangkan diri dan mengikuti lingkungan kehidupan. Dengan bekerja sebagai buruh wanita terlebih dahulu melakukan pekerjaan rumah tangga dan setelah itu bekerja sebagai buruh. Meskipun bekerja sebagai buruh, wanita tidak meninggalkan perannya sebagai ibu rumah tangga (Sinadia, 2017).

Menurut (Kesselman, 1999) mengatakan bahwa pekerjaan rumah tangga yang dilakukan oleh wanita sangat menguras tenaga dan waktu. Pekerjaan rumah tangga bahkan dilakukan sebelum matahari terbit, hingga anak-anak berangkat sekolah dan suami bekerja. Ketika anak dan suami pulang, masih mempersiapkan makanan. Bahkan malam terkadang masih harus mendampingi anak belajar. Sementara itu keterlibatan peran laki-laki dalam pekerjaan rumah tangga sangat jarang, utamanya pekerjaan sebagai kepala keluarga mencari nafkah.

Terlibatnya wanita dalam dunia pekerjaan atau ketenagakerjaan guna menambah penghasilan, terkadang mengharuskan wanita tersebut untuk melakukan migrasi. Perempuan biasanya melakukan migrasi bersama suami, ikut keluarga, atau ajakan teman (Soebyakto, 2016). $\mathrm{Hal}$ ini berbeda karakteristik dengan sebagian besar tenaga kerja wanita pada usaha emping melinjo di Desa Plumbon Kabupaten Batang, yang merupakan tenaga kerja "commuter/ulang-alik" atau dalam istilah Jawa "nglaju"

Usaha emping melinjo sangat berkembang di Kabupaten Batang dengan jumlah unit usaha mencapai 6.250 unit dan mampu menyerap tenaga kerja sebanyak 18.662 orang. Usaha emping melinjo tersebar di 8 kecamatan di Kabupaten Batang yaitu Kecamatan Bawang, Tersono, Subah, Banyuputih, Limpung, Blado, Reban dan Pecalungan. Sentra pembuatan pengolahan melinjo di Kabupaten Batang terletak di Kecamatan Limpung. Daerah Limpung dikenal sebagai penghasil produk emping melinjo terbesar di Kabupaten Batang, dimana di Kecamatan Limpung terdapat industri pengolahan emping melinjo tepatnya di Desa Plumbon. Terdapat 3 Usaha Dagang (UD) di Desa Plumbon diantaranya yaitu UD. Dua Melati, UD. Kencana Manunggal dan UD. Dadi Makmur (Badan Pusat Statistik, 2018).

Tanaman melinjo (Gnetum gnemon L.) merupakan salah satu tanaman yang mempunyai potensi cukup besar untuk dikembangkan dan tersebar hampir di semua wilayah kecamatan di Kabupaten Batang. Daun melinjo yang muda dapat diolah sebagai sayuran dan buah melinjo yang sudah tua dapat diolah sebagai bahan baku pembuatan emping. Sementara di sisi lain, industri pengolahan emping melinjo juga menyerap banyak tenaga kerja wanita, yang tidak mensyaratkan tingkat pendidikan dan pekerjaannya mudah dilakukan. Pekerjaan yang dilakukan oleh tenaga kerja wanita adalah menggoreng melinjo menggunakan pasir dan menggepuk melinjo. Adanya usaha emping melinjo ini dapat memberikan tambahan penghasilan bagi tenaga kerja wanita yang memiliki pendidikan rendah dan wanita dapat mengaktualisasikan diri selain sebagai ibu rumah tangga.

Usaha dagang emping melinjo di Desa Plumbon mampu menyerap tenaga kerja wanita di wilayah sekitar usaha dagang itu berdiri. Kebutuhan tenaga kerja wanita pada usaha 
emping ini menjadi peluang bagi para wanita untuk berpartisipasi terhadap peningkatan pendapatan keluarga. Berdasarkan uraian diatas, maka tujuan penelitian untuk mengetahui alasan tenaga kerja wanita bekerja pada usaha emping melinjo, alokasi waktu tenaga kerja wanita pada usaha emping melinjo, besar kontribusi pendapatan tenaga kerja pada usaha emping melinjo dan faktor yang mempengaruhi kontribusi pendapatan wanita pada usaha emping melinjo.

\section{METODE PENELITIAN}

Metode dasar yang digunakan dalam penelitian ini adalah metode deskriptif. Penentuan lokasi ditentukan dengan cara purposive sampling, yaitu di Desa Plumbon Kecamatan Limpung Kabupaten Batang sebagai salah satu desa yang terdapat usaha pembuatan emping melinjo di Kecamatan Limpung. Desa Plumbon memiliki 4 usaha dagang (UD) yang memproduksi emping melinjo, sedangkan yang masih aktif hanya 3 UD.

Adapun metode pengambilan sampel responden dilakukan dengan menggunakan metode random sampling atau pengambilan sampel secara acak sederhana, dengan melibatkan 45 tenaga kerja wanita. 45 tenaga kerja wanita tersebut berasal dari 3 usaha dagang (UD) yang ada di Desa Plumbon. Adapun rincian responden dapat dilihat pada Tabel 1.

Tabel 1. Rincian pengambilan sampel responden

\begin{tabular}{|c|c|c|c|}
\hline No & $\begin{array}{l}\text { Nama } \\
\text { Dagang }\end{array}$ & $\begin{array}{l}\text { Jumlah } \\
\text { Pekerja } \\
\text { Wanita }\end{array}$ & $\begin{array}{l}\text { Jumlah } \\
\text { Sampel }\end{array}$ \\
\hline 1 & Dua Melati & 50 & 14 \\
\hline 2 & Kencana Manunggal & 60 & 17 \\
\hline 3 & Dadi Makmur & 50 & 14 \\
\hline & Jumlah & 160 & 45 \\
\hline
\end{tabular}

Sumber: Analisis Data Primer, 2020

Sementara data yang digunakan, data primer dihasilkan dari wawancara langsung kepada tenaga kerja wanita yang dilibatkan dalam penelitian dan data sekunder didapatkan dari Kantor Kelurahan Desa Plumbon. Data yang diambil yaitu dalam satu bulan produksi di bulan Januari 2020.

Metode untuk menganalisis alokasi wanita bekerja pada usaha emping melinjo adalah dengan mentabulasi dan mendeskripsikan hasil wawancara dengan responden mengenai alokasi waktu wanita pada usaha emping melinjo. Guna mengetahui kontribusi pendapatan tenaga kerja pada usaha emping melinjo terhadap pendapatan keluarga digunakan analisa perbandingan antara besarnya pendapatan tenaga kerja dengan pendapatan rumah tangga (Rupiah/bulan), persamaan matematikanya yaitu:

$\mathrm{KTKW}=\left(\frac{\mathrm{PTKW}}{\mathrm{TPK}}\right) \times 100 \%$

Keterangan:

$K T K W$ : Kontribusi Tenaga Kerja Wanita pada usaha emping melinjo (\%)

PTKW : Pendapatan Tenaga Kerja Wanita pada usaha emping melinjo (Rupiah/bulan)

TPK : Total Pendapatan Keluarga (Rupiah/bulan).

Guna menganalisis faktor yang mempengaruhi kontribusi pendapatan tenaga kerja wanita pada usaha emping melinjo dengan menggunakan analisis regresi linear berganda. Variabel yang digunakan adalah pendapatan tenaga kerja wanita, pendapatan suami, dan jumlah tanggungan keluarga. Maka persamaannya dengan ditranformasikan ke dalam bentuk logaritma natural (ln), dapat dituliskan sebagai berikut :

$\operatorname{Ln} Y=a+b_{1} \ln X_{1}+b_{2} \ln X_{2}+b_{3} \ln X_{3}+e(2)$

Keterangan :

$Y$ : Kontribusi pendapatan tenaga kerja wanita pada usaha emping melinjo $(\%)$

$a$ : Konstanta

$b \quad$ : Koefisien regresi

$X_{1}$ : Pendapatan tenaga kerja wanita (Rupiah/bulan)

$X_{2} \quad$ : Pendapatan suami (Rupiah/bulan)

$X_{3} \quad$ : Jumlah tanggungan keluarga

$e \quad$ : Variabel Pengganggu

\section{HASIL DAN PEMBAHASAN}

\section{Karakteristik Tenaga Kerja Wanita}

Berdasarkan hasil penelitian, gambaran mengenai tenaga kerja wanita yang terlibat dalam penelitian, merupakan tenaga kerja 
wanita yang bekerja pada usaha emping melinjo di 3 usaha dagang (UD) pembuatan emping melinjo. Sebagian besar tenaga kerja wanita berada pada kisaran umur 50-59 tahun, sehingga rata-rata usia yaitu 52 tahun, dan masih termasuk kelompok umur yang produktif. Umur seseorang mempengaruhi prestasi kerja atau kinerja pekerja, semakin tua umur tenaga kerja, maka secara fisik akan menurun kekuatannya, sehingga akan turun pula prestasinya. Kekuatan fisik menurun akan mempengaruhi produktivitas seseorang. Stamina dan produktivitas yang menurun, akan cenderung mempengaruhi pendapatan yang diterima. Hal ini sependapat dengan penelitian (Christoper et al., 2017) yang menyampaikan variabel umur berpengaruh signifikan dan negatif terhadap pendapatan pekerja wanita dari rumah tangga miskin di Kecamatan Seberang Ulu II Kota Palembang. Faktor umur akan mempengaruhi produktivitas pekerja wanita tersebut dikarenakan umur sangat mempengaruhi stamina dan produktivitas tenaga kerja dalam melakukan aktifitasnya (dalam hal ini bekerja yang memperoleh upah atau pendapatan). Semakin bertambahnya umur pada batas tertentu, terdapat kecenderungan stamina dan produktivitas akan menurun. Penurunan produktivitas pada pekerja usia lanjut sangat terlihat untuk pekerjaan dimana belajar dan kecepatan dibutuhkan. Tetapi di beberapa pekerja yang lebih tua, ada yang masih mampu mempertahankan tingkat produktivitas yang tinggi (Skirbekk, 2004).

Adapun jika ditinjau dari tingkat pendidikannya, tenaga kerja wanita pada usaha emping melinjo berpendidikan SD sebanyak $71,7 \%$. Tingkat pendidikan tidak menjadi syarat keharusan di banyak usaha agroindustri, sehingga banyak pekerja wanita yang bekerja di sektor ini. Ditinjau dari lama menekuni pekerjaan, tenaga kerja wanita pada usaha emping melinjo bekerja selama 1-10 tahun atau $64,4 \%$. Pengalaman kerja yang identik dengan lamanya seseorang bekerja pada pekerjaan yang sama atau sejenis, dapat menjadi penentu prestasi kerja. Pekerja akan menjadi lebih terampil dalam pekerjaannya. Pengalaman kerja akan meningkatkan produktivitas selama beberapa tahun, tetapi akan ada titik dimana pengalaman kerja tidak lagi berpengaruh terhadap produktivitas.

Tenaga kerja wanita bekerja dimulai dari jam 06.00 sampai sampai jam 11.00, rata-rata selama 5 jam per hari. Per minggu rutin 5-6 hari kerja. Jika menggunakan istilah under employment yang menunjukkan bahwa pekerja yang bekerja di bawah 40 jam per minggu maka keseluruhan tenaga kerja wanita yang bekerja di usaha emping di ketiga

Tabel 2. Data karakteristik tenaga kerja wanita berdasarkan umur, pendidikan dan lamanya menekuni pekerjaan

\begin{tabular}{|c|c|c|c|}
\hline No & Umur (Tahun) & Jumlah Tenaga Kerja (orang) & Persentase $(\%)$ \\
\hline \multirow[t]{5}{*}{1.} & $25-29$ & 2 & 4,4 \\
\hline & $30-39$ & 3 & 6,6 \\
\hline & $40-49$ & 11 & 24,5 \\
\hline & $50-59$ & 18 & 40 \\
\hline & $60+$ & 11 & 24,5 \\
\hline \multicolumn{2}{|c|}{ Jumlah } & 45 & 100 \\
\hline \multirow[t]{5}{*}{2} & Tingkat Pendidikan & Jumlah Tenaga kerja (orang) & Persentase $(\%)$ \\
\hline & Tidak Sekolah & 7 & 15,5 \\
\hline & SD & 32 & 71,1 \\
\hline & SMP & 6 & 13,4 \\
\hline & SMA & 0 & 0 \\
\hline \multicolumn{2}{|c|}{ Jumlah } & 45 & 100 \\
\hline \multirow[t]{4}{*}{3} & $\begin{array}{l}\text { Lamanya Menekuni } \\
\text { Pekerjaan (Tahun) }\end{array}$ & Jumlah Tenaga Kerja (orang) & Persentase $(\%)$ \\
\hline & $<1$ & 1 & 2,2 \\
\hline & $1-10$ & 29 & 64,4 \\
\hline & $11-20$ & 15 & 33,4 \\
\hline \multicolumn{2}{|c|}{ Jumlah } & 45 & 100 \\
\hline
\end{tabular}

Sumber: Analisis Data Primer, 2020 
UD tersebut termasuk kategori under employed. Jika diakumulasikan dalam per minggu dengan bekerja 5 jam per hari, hari kerja per minggu 6 hari, maka rata-rata tenaga kerja wanita bekerja 30 jam per minggu.

Tenaga kerja wanita terlibat dalam beberapa tahapan pembuatan emping melinjo seperti penggorengan biji melinjo dan pemipihan biji melinjo. Upah tenaga kerja wanita pada usaha emping melinjo yaitu sebesar Rp.30.000 - Rp.35.000 dalam satu hari bekerja. Upah tenaga kerja wanita dihitung per kilogram biji melinjo yang diproduksi. Sistem yang digunakan dalam pembayaran upah ini adalah sistem borongan. Tenaga kerja wanita dapat menghasilkan $10-12 \mathrm{~kg}$ emping melinjo setiap harinya. Pada UD. Dua Melati dan UD. Kencana Manunggal, setiap tenaga kerja wanita memproduksi $12 \mathrm{Kg}$ melinjo setiap harinya dengan besaran upah Rp.2.500/Kg. Sedangkan pada UD. Dadi Makmur, setiap tenaga kerja wanita memproduksi $10 \mathrm{Kg}$ per harinya dengan upah Rp.3.000/Kg. Adapun data karakteristik tenaga kerja wanita berdasarkan umur, pendidikan dan lamanya menekuni pekerjaan dapat dilihat pada Tabel 2.

\section{Alasan Wanita Bekerja dan Alokasi Waktu Kerja}

Berdasarkan Tabel 3 menunjukkan alasan wanita bekerja yaitu karena faktor ekonomi untuk membantu suami mencari tambahan penghasilan rumah tangga sebanyak 75,5\%. Kenyataan ini merupakan indikasi bahwa bekerjanya seorang tenaga kerja wanita

Tabel 3. Alasan wanita bekerja pada usaha emping melinjo

\begin{tabular}{llcr}
\hline No & Alasan & $\begin{array}{r}\text { Jumlah } \\
\text { (jiwa) }\end{array}$ & $\begin{array}{r}\text { Persentase } \\
(\%)\end{array}$ \\
\hline 1 & Faktor ekonomi & & \\
& Membantu suami/ & 34 & 75,5 \\
menambah & & \\
& $\begin{array}{l}\text { penghasilan keluarga } \\
\text { Memiliki }\end{array}$ & 11 & 24,5 \\
& penghasilan sendiri & & \\
2 & Faktor Sosial & \\
& Mengisi waktu luang & 17 & 37,8 \\
& $\begin{array}{l}\text { Dekat rumah } \\
\text { Tidak mensyaratkan } \\
\text { pendidikan }\end{array}$ & 14 & 31,2 \\
& $\begin{array}{l}\text { Tidak mensyaratkan } \\
\text { keterampilan }\end{array}$ & 1 & 28,8 \\
\hline
\end{tabular}

Sumber: Analisis Data Primer, 2020 pada usaha emping melinjo untuk membantu suami dalam memenuhi kebutuhan keluarga. Di perdesaan dan kalangan masyarakat menengah kebawah peran wanita bukanlah memilih bekerja atau tidak bekerja, tetapi harus bekerja untuk menopang kehidupan rumah tangganya.

Berdasarkan hasil penelitian, dapat dikemukakan bahwa alasan wanita bekerja pada usaha pembuatan emping melinjo dilihat dari faktor ekonomi dominan untuk mencari tambahan penghasilan rumah tangga atau membantu suami untuk memenuhi kebutuhan keluarga, dan faktor sosial dominan untuk mengisi waktu luang sebesar $37,8 \%$. Selaras dengan penelitian (Nurung, et al 2005) yang menyatakan bahwa alasan ekonomi untuk mencari tambahan pendapatan keluarga atau untuk membantu suami dalam memenuhi kebutuhan keluarga dominan sebesar $75 \%$. Sedangkan faktor sosial, alasannya untuk mengisi waktu luang sebesar $71,43 \%$.

\section{Kontribusi Pendapatan Wanita Pada Usaha Emping Melinjo}

Kontribusi pendapatan merupakan total penjumlahan dari pendapatan keluarga secara keseluruhan. Pendapatan dalam satu keluarga tidak hanya berasal dari kepala keluarga, melainkan masih ada pendapatan lain dari anggota keluarga lainnya yang memiliki pendapatan (Fauziah dan Soejono, 2019).

Berdasarkan hasil penelitian, diperoleh hasil rata-rata pendapatan wanita pada usaha emping melinjo memberikan kontribusi sebesar $33,68 \%$ per bulan. Hal ini didukung dengan penelitian (Amin, 2016) yang menyatakan bahwa kontribusi pendapatan wanita pada usaha emping melinjo terhadap pendapatan keluarga sebesar $61,71 \%$ (kontribusi pendapatan lebih dari 25\%). Kontribusi tenaga kerja wanita, pada penelitian (Amin, 2016), lebih tinggi dibandingkan yakni $61,71 \%$. Hal ini disebabkan adanya perbedaan, tenaga kerja wanita dalam penelitian ini merupakan tenaga kerja wanita yang bekerja di industri pengolahan emping melinjo (UD), sedangkan tenaga kerja wanita pada usaha emping melinjo yang bekerja di rumah atau pengolahan emping melinjo tersebut mandiri skala rumah tangga, sehingga waktu untuk mengalokasikan dalam usaha pengolahan emping tidak terbatas pada jam kerja. 
Saadah, M., Wahyuningsih, S., Awami, S. N., Sasongko, L. A.: Kontribusi Pendapatan...

Tabel 4. Kontribusi pendapatan tenaga kerja wanita pada usaha emping melinjo terhadap pendapatan keluarga

\begin{tabular}{llcc}
\hline $\begin{array}{l}\text { Pendapatan Tenaga Kerja Wanita (Rp/bulan) } \\
\text { Usaha Emping }\end{array}$ & 869.334 & $\begin{array}{c}\text { Pendapatan Keluarga } \\
\text { (Rp/bulan) }\end{array}$ & $\begin{array}{c}\text { Kontribusi } \\
(\%)\end{array}$ \\
\hline Usaha sampingan & 321.333 & 2.581 .556 & 33,68 \\
Total & 1.190 .667 & & \\
\hline
\end{tabular}

Sumber: Analisis Data Primer, 2020

Tabel 5. Hasil analisis regresi faktor-faktor yang mempengaruhi kontribusi pendapatan tenaga kerja wanita pada usaha emping melinjo

\begin{tabular}{llll}
\hline Variabel & Koefisien Regresi & t-Hitung & Prob.Sig \\
\hline Konstanta & $-10,407$ & $-0,771$ & 0,446 \\
Pendapatan Tenaga Kerja Wanita & 1,634 & 1,693 & $0,100^{* *}$ \\
Pendapatan Suami & $-0,466$ & $-4,448$ & $0,000^{*}$ \\
Jumlah Tanggungan & $-1,661$ & $-6,242$ & $0,000^{*}$ \\
\hline Koefisien Determinasi $\left(\mathrm{R}^{2}\right)$ & 0,686 & & \\
Adjust R Square & 0,658 & & $0,000^{*}$ \\
F hitung & 24,781 & \\
F tabel 1\% & 2,83 & & \\
t tabel 1\% & 2,70118 & \\
t tabel 10\% & 1,30254 & & \\
Durbin Watson & 1,740 & & \\
\hline
\end{tabular}

Sumber: Analisis Data Primer, 2020

Keterlibatan wanita dalam kegiatan ekonomi bukan sekedar emansipasi tetapi untuk meningkatkan pendapatan keluarga demi keberlangsungan hidup, Gambaran peningkatan mengenai kontribusi pendapatan wanita terhadap rata-rata total pendapatan keluarga per bulan pada usaha emping melinjo di Desa Plumbon Kecamatan Limpung Kabupaten Batang dapat dilihat pada Tabel 4.

Faktor yang Mempengaruhi Kontribusi Pendapatan Tenaga Kerja Wanita

Teknik yang digunakan untuk mengetahui faktor-faktor yang mempengaruhi kontribusi pendapatan tenaga kerja wanita menggunakan analisa regresi linier berganda yang ditransformasikan dalam bentuk logaritma natural $(\mathrm{ln})$, dengan program SPSS. Variabel terikat $(\mathrm{Y})$ adalah kontribusi pendapatan tenaga kerja wanita pada usaha emping melinjo terhadap pendapatan keluarga. Sebagai variabel bebasnya adalah pendapatan tenaga kerja wanita $\left(X_{1}\right)$, pendapatan suami $\left(X_{2}\right)$ dan jumlah tanggungan $\left(\mathrm{X}_{3}\right)$. Hasil analisis regresi antara variabel bebas dan variabel terikat digambarkan dalam Tabel 5.
Berdasarkan analisis data diatas, hasil pengujian menunjukkan bahwa variabel terbebas dari uji asumsi klasik dan memenuhi asumsi terdistribusi normal, meliputi uji normalitas, multikolinearitas, autokorelasi dan heteroskedastisitas sehingga model layak digunakan dalam penelitian.

Berdasarkan olah data statistik, menyatakan bahwa proporsi pengaruh variabel bebas (pendapatan tenaga kerja wanita, pendapatan suami dan tanggungan keluarga) terhadap variabel terikat (kontribusi pendapatan tenaga kerja wanita) sebesar $68,6 \%$, sedangkan sisanya $31,4 \%$ dipengaruhi oleh variabel lain yang tidak terdapat pada model regresi linear dalam penelitian ini. Berdasarkan uji F-statistik yang telah dilakukan, menunjukkan bahwa model regresi yang diestimasi layak dan variabel bebas secara keseluruhan bersamasama berpengaruh secara signifikan terhadap variabel terikat berupa kontribusi pendapatan wanita.

Pada output SPSS regresi linier berganda menunjukkan bahwa nilai koefisien regresi (b) dari variabel bebas berupa pendapatan wanita adalah 1,634. Hal ini dapat diterjemahkan bahwa setiap kenaikan satu $1 \%$ pendapatan wanita, maka akan diikuti oleh peningkatan 
kontribusi pendapatan wanita sebesar $1,634 \%$. Variabel pendapatan wanita secara statistik berpengaruh nyata terhadap kontribusi pendapatan tenaga kerja wanita pada usaha emping melinjo linear dengan penelitian (Rahaju et al., 2012) yang menyatakan bahwa pendapatan ibu berpengaruh secara signifikan terhadap kontribusi pendapatan.

Berdasarkan hasil analisa dapat diketahui bahwa variabel bebas pendapatan suami menunjukkan bahwa nilai koefisien regresi sebesar -0,466. Nilai koefisien bertanda negatif, dapat diartikan setiap kenaikan pendapatan suami sebesar satu $1 \%$, maka kontribusi pendapatan tenaga kerja wanita mengalami penurunan sebesar $0,466 \%$. Variabel pendapatan suami secara statistik berpengaruh nyata terhadap kontribusi pendapatan wanita pada usaha emping melinjo. Semakin meningkat pendapatan suami, semakin menurun jumlah kontribusi pendapatan wanita pada usaha emping melinjo. Linear dengan penelitian (Ramadhan, 2004) yang menyatakan bahwa pendapatan suami secara parsial berpengaruh signifikan terhadap kontribusi pendapatan tenaga kerja wanita.

Hasil analisis menunjukkan bahwa nilai koefisien regresi sebesar -1,661. Nilai koefisien bertanda negatif, dapat diartikan setiap kenaikan jumlah tanggungan keluarga, maka kontribusi pendapatan wanita mengalami penurunan sebesar $1,661 \%$. Variabel jumlah tanggungan keluarga secara statistik berpengaruh nyata terhadap kontribusi pendapatan wanita pada usaha emping melinjo.

\section{KESIMPULAN}

Alasan tenaga kerja wanita bekerja pada usaha pembuatan emping melinjo dilihat dari faktor ekonomi dominan untuk mencari tambahan penghasilan rumah tangga atau membantu suami untuk memenuhi kebutuhan keluarga sedangkan dilihat dari faktor sosial yaitu untuk mengisi waktu luang. Rata-rata alokasi waktu tenaga kerja wanita mengalokasikan waktunya untuk kegiatan produktif terbanyak sebesar 8 jam per hari untuk mencari nafkah, selama 5 jam untuk bekerja pada usaha emping melinjo dan 3 jam untuk bekerja diluar usaha emping melinjo atau pekerjaan sampingan. Kontribusi pendapatan tenaga kerja wanita pada usaha emping melinjo rata-rata sebesar $33,68 \%$.
Faktor-faktor yang mempengaruhi kontribusi pendapatan wanita meliputi pendapatan wanita, pendapatan suami dan jumlah tanggungan.

Saran bagi tenaga kerja wanita, hendaknya menjalankan tugasnya di dalam kegiatan sosial dan kegiatan ekonomi dengan sama baiknya, tanpa harus mementingkan salah satu peran dan mengorbankan peran lainnya. Bagi pemilik usaha, perlu adanya inovasi produk agar mampu bersaing dengan produk lainnya, misal dengan menambahkan varian rasa di produk emping melinjo yang diproduksi, sehingga juga akan memberikan lebih banyak kesempatan kerja bagi wanita. Bagi pemerintah daerah, perlu adanya pemberdayaan wanita melalui pendidikan di kelompok wanita dan sejenisnya guna meningkatkan kualitas SDM diluar kegiatan bekerja sehingga mereka kedepannya dapat berperan positif dalam kesejahteraan keluarga.

\section{DAFTAR PUSTAKA}

Amin, M. N. (2016). Kontribusi tenaga kerja wanita pada usaha emping melinjo terhadap pendapatan keluarga. Jurnal Mediagro, 12(2), 26-38.

Badan Pusat Statistik. (2018). Badan Pusat Statistik. Kabupaten Batang Dalam Angka. Batang: BPS Kab. Batang.

Christoper, R., Chodijah, R. \& Yunisvita (2017). Faktor-faktor yang mempengaruhi pendapatan pekerja wanita sebagai ibu rumah tangga. Jurnal Ekonomi Pembangunan, 15(1), 35-52.

Fauziah, F. R., \& Soejono, D. (2019). Analisis pendapatan usahatani jamur merang dan kontribusinya terhadap pendapatan rumah tangga petani di Kelurahan Sempursari Kecamatan Kaliwates Kabupaten Jember. SEPA, 15(2), 172179.

Kesselman, A. (1999). Women Imagesand Realities; A Multicultural Anthology. (Second Edition). Mayfiels Publising Company.

Nurung, M., Priyono, B. S., \& Yuniarti, F. (2005). Analisis curahan waktu kerja dan 
hubungannya dengan pendapatan wanita pedagang pengecer sayuran. Jurnal Agrisep, 14, 1.

Rahaju, M. E. E., Mulyati, T., \& Sumarlan. (2012). Motivasi wanita bekerja dan pengaruhnya terhadap kontribusi pendapatan keluarga (Studi kasus di Kecamatan Taman Kota Madya Madiun). Jurnal Penelitian Ekomaks Fakultas Ekonomi Universitas Merdeka. Madiun, 1(2), 80-94.

Ramadhan. (2004). Kontribusi pendapatan perempuan tani pada usahatani padi sawah terhadap pendapatan keluarga di Desa Lhok Keutapang Kecamatan Tangse Kabupaten Pidie [Electronic Thesis and Dissertation Universitas Syiah Kuala Darussalam]. Banda Aceh.
Sinadia, J. B. C., M.Wangke, W., \& M.Benu, N. (2017). Kontribusi buruh perempuan terhadap pendapatan keluarga (Studi kasus tempat pelelangan ikan di Tumumpa Kota Manado). Jurnal Penelitian Agri-Sosio Ekonomi Unsrat. Manado, 13, 253-260.

Skirbekk, V. (2004). Age and individual productivity: A literature survey, Vienna Yearbook of Population Research, 2(1), 133-154.

Soebyakto, B. B. (2016). Migrant women working at informal sectors: Empirical study in Kuto Batu Village, Ilir Timur Ii Palembang City. International Journal of Humanities and Social Science, 6(4), 125-137. 